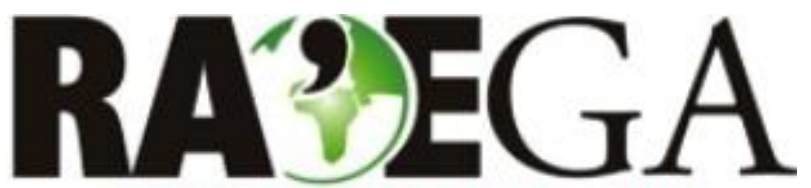

O ESPACCO GEOGRÁFICO EM ANÁLISE

\title{
ANÁLISE GEOMORFOLÓGICA APLICADA AOS ESTUDOS DE VIAS DE TRANSPORTE TERRESTRE NO BRASIL
}

\section{GEOMORPHOLOGICAL ANALYSIS APPLIED TO STUDIES OF TERRESTRIAL TRANSPORT ROUTES IN BRAZIL}

\section{RESUMO}

\author{
Tony Vinicius Moreira Sampaio $^{1}$ e Carlos Henrique Sopchaki ${ }^{2}$
}

Estudos envolvendo geomorfologia são utilizados em diversas áreas, possibilitando o entendimento dos processos ambientais que modelam a superfície da Terra e afetam a segurança e o desenvolvimento humano. A análise geomorfológica é fundamental para o planejamento territorial e ambiental, devendo subsidiar a realização de projetos e obras em qualquer escala espacial de análise. Neste sentido, a análise geomorfológica integra os estudos relativos à caracterização do meio físico no que concerne à vias de transporte terrestre, como rodovias e ferrovias. Destaca-se que a análise geomorfológica é parte obrigatória dos estudos sobre vias de transporte terrestre em território brasileiro, sendo a responsável pela caracterização dos processos, materiais e formas que afetam a segurança destas. Sendo assim, o objetivo deste artigo é propor uma reflexão acerca do potencial da análise geomorfológica aplicada ao planejamento, implantação e recuperação de vias de transporte terrestre de variadas dimensões (centenas de metros a centenas de quilômetros), abordando temas como fontes de dados, inventário de campo, diversidade metodológica, condicionantes para escolha da abordagem metodológica, limitações impostas pela escala, utilização de modelos digitais de representação do relevo e adequação das áreas de influência direta e indireta.

PALAVRAS-CHAVE: Geomorfologia, Mapeamento Geomorfológico, Rodovias, Ferrovias.

\section{ABSTRACT}

Studies involving geomorphology are used in several areas, making it possible to understand the environmental processes that shape the Earth's surface and affect human security and development. Geomorphological analysis is fundamental for territorial and environmental planning, and should support the execution of projects and works in any spatial scale of analysis. In this sense, geomorphological analysis integrates the studies related to the characterization of the physical environment of terrestrial transport routes, such as highways and railroads. It should be emphasized that geomorphological analysis is a mandatory part of the studies on terrestrial transport routes in Brazil, being responsible for the characterization of the processes, materials and forms that affect the safety of these. The objective of this article is to propose a reflection about the potential of the geomorphological analysis applied to the planning, implementation and recovery of terrestrial transport routes of several dimensions (hundreds of meters to hundreds of kilometers), addressing issues such as data sources, field inventory, methodological diversity, constraints for choosing the methodological approach, limitations imposed by scale, use of digital models of relief representation and adequacy of areas of direct and indirect influence.

KEY-WORDS: Geomorphology, geomorphological mapping, highways, railways..

\footnotetext{
${ }^{1}$ Universidade Federal do Paraná/PR, e-mail: tony2sampaio@gmail.com

${ }^{2}$ Universidade Federal do Paraná/PR, e-mail: csopchaki@gmail.com
} 


\section{ANÁLISE GEOMORFOLÓGICA APLICADA AOS ESTUDOS DE VIAS DE TRANSPORTE TERRESTRE NO \\ BRASIL}

\section{INTRODUÇÃO}

A análise geomorfológica possui amplo espectro de aplicação e possibilita o entendimento dos processos ambientais que modelam a superfície da Terra, afetando a segurança e o desenvolvimento das atividades humanas.

Seu conhecimento é fundamental para o planejamento territorial e ambiental, devendo subsidiar a realização de projetos e obras em qualquer escala espacial de análise.

A análise geomorfológica pode envolver a elaboração de mapas, que servem de base para elaboração de cenários ambientais, para identificação e delimitação de áreas de risco e dos passivos ambientais presentes ou decorrentes dos diferentes tipos de empreendimentos.

A geomorfologia está inserida na caracterização do meio físico nos estudos inerentes à empreendimentos lineares, como rodovias e ferrovias, integrando-se com outros dados, como pedologia, clima, geologia e recursos hídricos.

Os estudos geomorfológicos aplicados ao planejamento de Vias de Transporte Terrestre (VTT) devem gerar como resultado um relatório técnico e um mapa geomorfológico, trazendo subsídio para decisões de planejamento e engenharia, buscando evitar, mitigar e compensar os impactos mais significativos nas fases de planejamento, execução e operação.

Cabe destacar que, no Brasil, não há diretrizes claras no tocante ao encaminhamento metodológico e definição de escala nos estudos e mapeamentos geomorfológicos, gerando uma dificuldade de integração de dados e padronização metodológica.

Este artigo apresenta uma reflexão acerca das fontes de dados, metodologias, limitações e potencial da análise geomorfológica aplicada ao planejamento, implantação e recuperação de VTT.

Para tanto, toma como referência a análise de estudos e documentos técnicos que abordam a temática, além de estudos executados em ferrovias (públicas e privadas) e rodovias estaduais e federais.

A ênfase da abordagem é a capacidade de aplicação da análise geomorfológica como base para o planejamento e a intervenção em vias de variadas dimensões (centenas de metros a centenas de quilômetros).

\section{ANÁLISE GEOMORFOLÓGICA NO CONTEXTO DOS ESTUDOS SOBRE VIAS DE TRANSPORTE TERRESTRE}

No contexto de empreendimentos lineares, como rodovias e ferrovias, a análise geomorfológica integra os estudos relativos à caracterização do meio físico. Esta caracterização demanda, ainda, dados sobre geologia, pedologia, clima, recursos hídricos, ruídos e qualidade do ar (DNIT, 2006).

A análise geomorfológica fornece informações relevantes para a realização e entendimento dos demais estudos sobre o meio físico, bem como se utiliza dos dados obtidos por estes levantamentos. Seu estudo pode anteceder, proceder ou integrar, de forma simultânea, a realização dos demais levantamentos que caracterizam o meio físico (Fig. 1). 


\section{ANÁLISE GEOMORFOLÓGICA APLICADA AOS ESTUDOS DE VIAS DE TRANSPORTE TERRESTRE NO BRASIL}

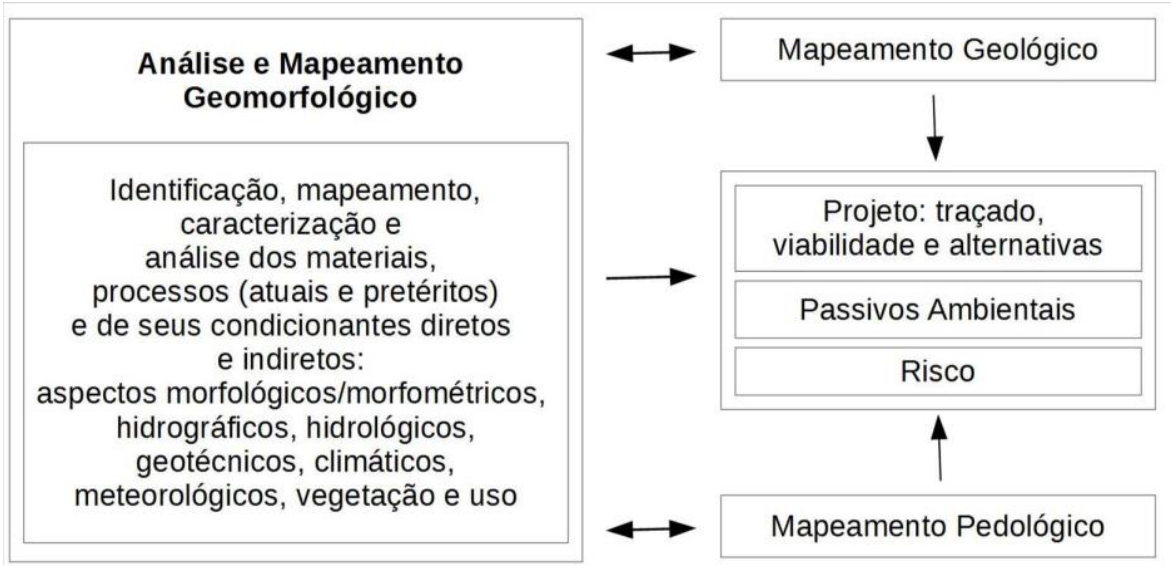

Figura 01 - Mapeamento Geomorfológico aplicado à análise de vias de transporte terrestre - capacidade de síntese e integração de dados. Fonte: elaborado pelos autores (2015).

Aplicada ao estudo e planejamento de vias de transporte terrestre (VTT), a análise geomorfológica demanda a produção de um relatório técnico e de um mapa geomorfológico, os quais fornecem informações relevantes para a elaboração dos projetos de engenharia e, para a implantação e funcionamento das vias.

Tanto o relatório quanto o mapa devem apresentar informações sobre as áreas de influência direta e indireta das vias, possibilitando evitar, mitigar e compensar os impactos mais significativos das fases de planejamento, execução e operação.

As diretrizes para a execução do relatório e do mapa geomorfológico são estabelecidas pelos órgãos contratantes e/ou fiscalizadores, como a exemplo DNIT (Departamento Nacional de Infraestrutura de Transportes), DER's (Departamentos Estaduais de Estradas de Rodagem) e a VALEC - Engenharia, Construções e Ferrovia S.A. (empresa pública vinculada ao Ministério dos Transportes).

Em geral estas diretrizes encontram-se explicitadas em Termos de Referência (TR) ou Instruções Técnicas (IT), os quais normatizam os estudos necessários para a elaboração do projeto, implantação e funcionamento da via.

Os TR e IT, em geral, não estabelecem a metodologia que deve ser empregada na análise geomorfológica, bem como a escala (cartográfica) do mapeamento, porém explicitam que a metodologia deve ser citada e, que os mapas devem apresentar escala compatível com as necessidades do empreendimento.

\footnotetext{
“Apresentar a metodologia empregada para levantamento dos dados e informações que subsidiaram o detalhamento de cada item relacionado ao Meio Físico, apresentando a forma e andamento dos trabalhos de levantamento de dados primários e/ou secundários (INEA, 2015)."
}

O relatório técnico deve ser elaborado tanto com dados obtidos diretamente em campo (dados primários), como com aqueles disponibilizados por outras fontes de dados (dados secundários).

O relatório deve apresentar foco na caracterização e descrição das unidades geomorfológicas e deve propiciar a análise conjunta de materiais, processos (atuais e pretéritos) e formas presentes na área de interesse. Também deverá permitir a associação dos dados geomorfológicos aos demais dados do meio físico.

O relatório técnico com a caracterização geomorfológica serve como fonte de dados primários e, ao mesmo tempo, como documento de síntese, uma vez que fornece informações necessárias ao entendimento e planejamento do ambiente como um todo.

Por sua vez, o mapa geomorfológico apresenta a compartimentação da área de interesse em segmentos com diferentes 


\section{ANÁLISE GEOMORFOLÓGICA APLICADA AOS ESTUDOS DE VIAS DE TRANSPORTE TERRESTRE NO \\ BRASIL}

dinâmicas e distintas características físicoambientais.

Cada unidade sintetiza a interação e a integração dos processos e materiais (geologia e solos) presentes e pretéritos associados às formas de relevo. Representa, portanto, a memória do sistema ambiental analisado, o que permite a reconstrução e a avaliação de sua dinâmica, bem como de possíveis impactos decorrentes da implantação da via e no ambiente, ao longo da via.

Cada unidade geomorfológica mapeada apresenta nível de similaridade interna que a diferencia em relação às unidades vizinhas. 0 grau de similaridade é função da análise das tipologias e interações entre materiais, processos e formas.

É necessário, portanto, apresentar descrição detalhada de cada unidade geomorfológica mapeada, contemplando formas e processos atuantes, bem como declividade e presença ou propensão a acidentes geológicogeomorfológicos (processos erosivos, assoreamento, subsidências, áreas sujeitas à inundações, entre outros) em escala que permita relacionar as formas e processos com as alterações propostas pelo empreendimento.

\section{LIMITAÇõES DA ANÁLISE GEOMORFOLÓGICA APLICADA AO ESTUDO DE VIAS DE TRANSPORTE TERRESTRE}

No Brasil inexistem diretrizes que auxiliem na escolha metodológica e definição da escala a ser empregada em estudos e mapas geomorfológicos de âmbito geral (locais, regionais, estaduais ou de abrangência nacional).

Com exceção dos TRs e ITs, que explicitam a necessidade de citar a metodologia escolhida e adequar a escala do mapeamento as necessidades do estudo, não existem regras formais que disciplinem ou subsidiem a escolha destes itens para aplicação nos diferentes níveis de análise demandados pelas VTTs.

Esta lacuna, positiva no sentido de flexibilizar a escolha da metodologia e da escala, trás como consequência negativa a dificuldade de integração dos dados, de padronização metodológica e de escala e, principalmente, de avaliação do grau de adequação dos produtos empregados nestes estudos.

No que se refere à elaboração e execução de projetos para VTTs é possível identificar e diferenciar, informalmente, três níveis de estudos, os quais demandam diferentes abordagens e escalas de análises: estudos de viabilidade, planejamento e projeto. Estes estudos podem ser demandados de forma isolada ou conjunta (três níveis).

Estudos de viabilidade correspondem àqueles realizados na etapa de implantação de novas e, em geral, extensas VTTs. Empregam dados geomorfológicos diversos sobre a área candidata ao recebimento da via, em geral de fontes secundárias e em escala inferior a 1:50.000. Objetivam subsidiar o traçado da via, considerando aspectos integrados sobre: formas, processos, hidrografia, clima, geologia e pedologia.

Estudos no nível de planejamento objetivam subsidiar obras de duplicação, pavimentação, recuperação, manutenção e estabilidade de vias. Estes empregam dados de fontes primárias e secundárias, fornecendo informações relevantes sobre condicionantes, alternativas de traçado, disponibilidade de materiais, passivos ambientais, processos atuantes, entre outras (escalas entre 1:5.000 e 1:50.000). Os estudos desta natureza são recorrentes e, em geral, condicionados a realização de levantamentos e do mapeamento geomorfológico.

Estudos no nível de projeto são menos usuais quanto à demanda por mapas e estudos geomorfológicos. Utilizam dados preferencialmente primários em escala de detalhe (em geral em escala melhor do que 1:5.000). Estes estudos incluem estratégias de estabilidade e custos e possuem relação direta com os dados derivados da análise geotécnica.

No Brasil, a maior parte dos dados e mapas geomorfológicos disponíveis como fonte secundária de dados (estudos já realizados) não atende aos três níveis de análise e, em especial, às demandas de planejamento e projeto. Isto 


\section{ANÁLISE GEOMORFOLÓGICA APLICADA AOS ESTUDOS DE VIAS DE TRANSPORTE TERRESTRE NO \\ BRASIL}

porque, em sua maioria, os dados e mapas disponíveis são baseados em metodologias com viés na compartimentação de grandes unidades territoriais e, consequentemente, apresentam baixo nível de detalhamento.

Estes estudos, por si só, não são suficientes para a análise geomorfológica nos níveis de análise mais demandados para os estudos de VTTs, para fins de recuperação e duplicação de vias, os quais carecem de uma abordagem metodológica diferenciada e maior nível de detalhamento.

Por apresentar foco diferenciado em relação à demanda dos estudos para VTTs, os mapeamentos disponíveis no Brasil em maior quantidade apresentam escala pequena e são úteis preferencialmente para o nível de análise de viabilidade. Quando a VTT é muito extensa (dezenas a centenas de quilômetros), estes estudos e mapas podem subsidiar, mas não de forma isolada, o planejamento de traçado e o estudo de alternativas.

Por vezes os estudos em nível de planejamento e projeto são elaborados de forma equivocada empregando dados pouco detalhados, obtidos a partir de fontes secundárias. Isto faz com que a análise geomorfológica perca sua relevância, uma vez que dados e mapas em escala reduzida podem não caracterizar as unidades transpostas pelas vias, não descrevendo processos atuantes e as formas e materiais envolvidos.

O uso de dados e mapas muito generalizados nestes estudos (informações pouco detalhadas em escala) e que empregam metodologia inadequada decorre da falta de dados geomorfológicos detalhados para o território brasileiro e muitas vezes, do desconhecimento sobre os itens relevantes que devem ser considerados no planejamento da via em suas diferentes escalas.

\subsection{DIVERSIDADE E FALTA DE PADRONIZAÇÃO METODOLÓGICA COMO FATOR LIMITANTE PARA A INTEGRAÇÃO DE DADOS}

O mapeamento geomorfológico pode ser realizado a partir da aplicação de diferentes metodologias. No Brasil as mais utilizadas são as do Projeto RADAMBrasil (que não se trata de uma metodologia única, sendo sua primeira proposta publicada em 1973), de Ross (1992) e as de IBGE (2005), que se desdobram das propostas citadas anteriormente e apresentam pequenas diferenças.

São trabalhos que abarcam grandes dimensões territoriais e apresentam grande nível de generalização cartográfica. Desta forma, estes estudos são fundamentais na etapa de estudo de viabilidade e, no caso de vias extensas, para fins de planejamento do traçado das vias, fornecendo simultaneamente informações sobre compartimentos geológicos e pedológicos. Contudo, estes mapeamentos apresentam pouca utilidade para estudos em nível de planejamento e de projeto, principalmente para vias menores (quilômetros ou dezenas de quilômetros).

Estas metodologias têm como base o ordenamento dos fatos geomorfológicos, de acordo com uma classificação temporal e espacial, na qual se distinguem os modelados como unidades básicas e seus grupamentos hierárquicos, como por exemplo, os presentes na proposta metodológica do IBGE (2005): Domínios Morfoestruturais, Regiões Geomorfológicas, Unidades Geomorfológicas, Modelados e Formas de Relevo Simbolizadas.

Os estudos e mapas geomorfológicos que empregam estas metodologias apresentam maior recobrimento sobre o território brasileiro, e são disponibilizados em geral nas escalas 1:250.000 (IBGE) e 1:1.000.000 (RADAMBrasil).

Empregam como base o procedimento metodológico denominado de divisão lógica no qual a unidade maior é compartimentada na medida em que são inseridos e avaliados atributos em sucessivos níveis de análise (táxons), processo também denominado de "Pesquisas Ambientais Multitemáticas" (Ross, 1995).

Trata-se de um "processo dedutivo, de cima para baixo (top-down)" (Medeiros e Câmara, 2001), que pressupõe conhecimento prévio do todo, o qual é "subdividido analiticamente até chegar a suas partes 


\section{ANÁLISE GEOMORFOLÓGICA APLICADA AOS ESTUDOS DE VIAS DE TRANSPORTE TERRESTRE NO \\ BRASIL}

componentes (indivíduos, objetos ou entidades)".

Apesar de amplamente difundidas, estas propostas apresentam limitações quanto à aplicação dos procedimentos operacionais e atribuição de parâmetros quantitativos, o que dificulta a uniformização e definição de suas subunidades, conforme já demonstrado por Sampaio e Augustin (2008; 2014).

Também não definem as regras de generalização cartográfica necessárias para adequar os níveis taxonômicos às diferentes escalas de aplicação do mapeamento geomorfológico demandado nos níveis de planejamento e projeto.

Por estes motivos, diferentes classificações são possíveis para uma mesma área, como a exemplo dos mapeamentos geomorfológicos dos estados de São Paulo e Paraná, que apesar de adotarem a mesma metodologia apresentam classificações distintas para áreas idênticas e contíguas, podendo gerar problemas para o enquadramento das vias.

A falta de padronização metodológica é citada por diversos autores que apresentam e empregam estas metodologias (RADAMBRASIL, 1973; ROSS, 1992; IBGE, 2005). Como consequência são observadas incongruências de diferentes ordens, o que dificulta a integração dos dados e impossibilita a geração de produtos finais padronizados e condizentes com as diferentes escalas demandadas.

O próprio IBGE (2005) sugere que novas abordagens, adequações e propostas sejam feitas para ampliação e aplicação dos estudos geomorfológicos.

\subsection{LIMITAÇÕES IMPOSTAS PELA ESCALA}

As escalas cartográficas dos mapeamentos geomorfológicos de maior cobertura espacial no Brasil são incompatíveis com boa parte das necessidades dos estudos que subsidiam o planejamento de VTTs. Estes mapeamentos apresentam grande nível de generalização cartográfica, englobando diferentes unidades dentro de um único compartimento geomorfológico.
Ao longo do traçado das VTTs, toda e qualquer alteração de forma, materiais e processos constituem informações relevantes que necessitam ser descritas em relação às suas influências sobre o traçado e estabilidade do ambiente e das vias. Da mesma forma, devem ser consideradas as influências das VTTs sobre as unidades geomorfológicas.

A demanda apresentada nos Termos de Referência indica que os estudos e mapeamentos devem ser compatíveis com a escala dos empreendimentos, os quais, em sua maioria, são de pequenas dimensões. Isto demonstra a necessidade de bases cartográficas com elevado nível de detalhamento.

Em se tratando de implantação e recuperação de vias, é comum a demanda por estudos e mapas para reduzidos seguimentos (trechos com poucos quilômetros de extensão), o que resulta em produtos finais em escalas maiores do que 1:50.000 (em geral maiores que 1:20.000, podendo chegar a 1:2.000), a depender da extensão da via e da complexidade dos ambientes transpostos.

Desta forma, é comum que uma VTT inteira se encontre dentro de apenas uma unidade geomorfológica mapeada nas bases cartográficas em escalas de maior cobertura no Brasil sendo, portanto, de pouca ou nenhuma utilidade para o planejamento da mesma.

A informação isolada de que todo trecho de uma VTT se encontra, por exemplo: na Unidade Geomorfológica do Domínio Colinoso Mar de Morros, é inadequada ao planejamento e intervenção direta na via, pois contrasta com os objetivos da análise geomorfológica em estudos de VTTs (Fig. 2). Isto porque, ao longo da via podem ser observadas distintas unidades com diferentes formas, materiais, origens e processos condicionantes (Fig. 3). 


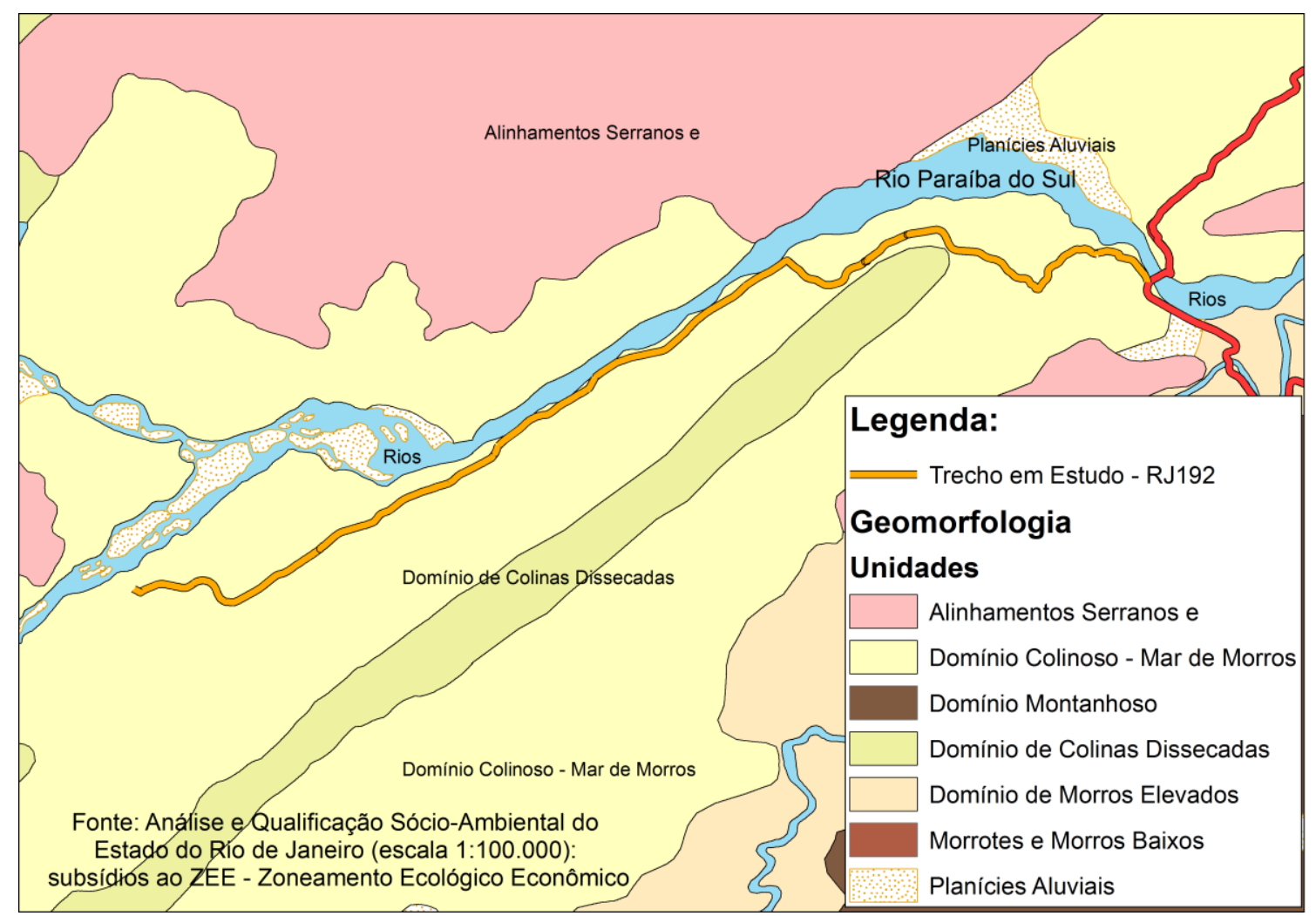

Figura 02 - VTT assentada sobre a Unidade Domínio Colinoso - Mar de Morros, conforme dados secundários obtidos na escala 1:100.000.Fonte: organizado pelos autores (2015).

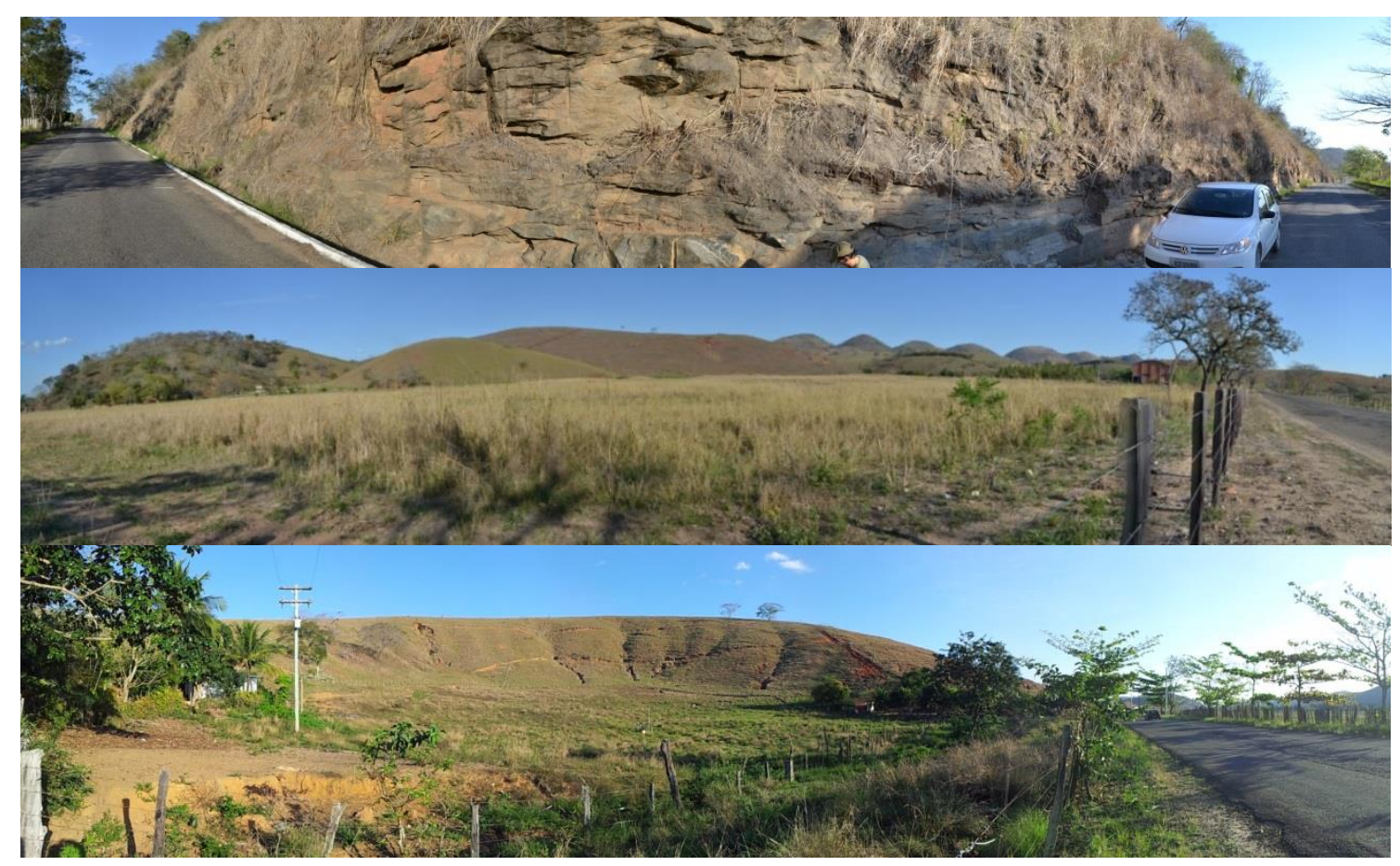

Figura 03 - Diferentes formas, materiais, origens e processos ao longo da mesma VTT.Fonte: acervo dos autores (2013). 


\section{ANÁLISE GEOMORFOLÓGICA APLICADA AOS ESTUDOS DE VIAS DE TRANSPORTE TERRESTRE NO \\ BRASIL}

Estudos e mapas em escalas menores são relevantes principalmente para trechos extensos como no caso de ferrovias, que podem chegar a $1500 \mathrm{Km}$ de extensão (exemplo: Ferrovia Oeste-Leste - FOL EF334) (OIKOS, 2010).

Contudo, trabalhos com VTTs com dimensões menores são mais recorrentes e demandam estudos mais aprofundados, em escalas maiores, principalmente para as etapas de implantação e operação.

Outras limitações relativas aos dados secundários de escala reduzida residem na baixa abrangência territorial e na dificuldade de integração dos mesmos. O único mapeamento geomorfológico que recobre todo território nacional empregando metodologia única encontra-se na escala 1:1.000.000.

Poucos Estados da Federação apresentam estudos em escalas maiores e nem sempre os mapeamentos empregam metodologia similar, e mesmo quando o fazem, os níveis de subjetividade das diversas metodologias podem gerar resultados de difícil integração.

A segunda escala de mapeamento geomorfológico com maior recobrimento no Brasil é a de 1:250.000, não disponível para todos estados da Federação. Esta escala é, também, incompatível com a demanda da maioria dos estudos de VTTs em função do nível de generalização empregado. Os mapas nestas escalas nem sempre empregam a mesma metodologia, o que gera divergência na nomenclatura e no limite das unidades geomorfológicas que recobrem dois ou mais estados.

São Paulo, Espírito Santo e Paraná são exemplos de estados que possuem mapeamentos na escala 1:250.000 empregando a metodologia proposta por Ross (1992).

Rio de Janeiro apresenta mais de um mapeamento, sendo um na escala 1:100.000 (Coelho Netto, 2008) e outro na escala 1:250.000 (CPRM, 2000), empregando diferentes metodologias. O Estado de Goiás apresenta mapeamento geomorfológico na escala 1:250.000 e emprega uma metodologia menos usual, a qual se baseia na Teoria de Sistemas (LATRUBESSE et. al, 2005).

Neste sentido, VTTs que transpassam limites de diferentes estados, com diferentes mapeamentos, dificilmente conseguem fazer uso dos mapas disponíveis em função das descontinuidades ou, das divergências de limites e nomenclatura das unidades mapeadas.

Dados em escalas maiores podem ser obtidos a partir de estudos e mapeamentos feitos para fins acadêmicos e de consultoria. Estes estudos, porém, apresentam outras limitações como, por exemplo: a baixa abrangência espacial, dificuldade de acesso aos dados, indisponibilidade dos dados cartográficos em formato digital e, falta de padronização metodológica (Fig. 4). 


\section{ANÁLISE GEOMORFOLÓGICA APLICADA AOS ESTUDOS DE VIAS DE TRANSPORTE TERRESTRE NO \\ BRASIL}

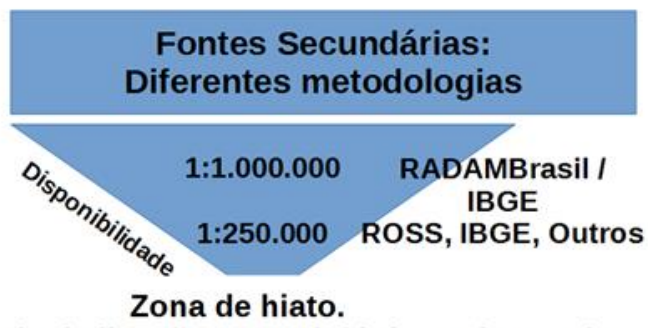

Dificuldade de ligação: metodológica e de escala

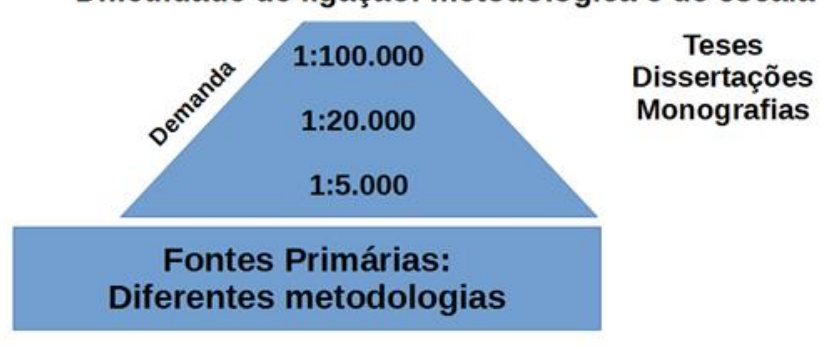

Figura 03 - As demandas de dados e mapas geomorfológicos para os estudos de VTTs são, em geral, incompatíveis com maioria dos dados disponíveis. A demanda maior é por estudos em grande escala. Fonte: organizado pelos autores (2015).

A Desta forma, o mapeamento geomorfológico aplicado à análise VTTs, exige cuidados no que diz respeito à delimitação de unidades geomorfológicas baseadas em dados secundários, principalmente no que concerne à integração dos dados em função das diferentes escalas e metodologias.

\subsection{LIMITAÇÕES DAS ANÁLISES MORFOLÓGICAS E MORFOMÉTRICAS COM O EMPREGO DE MODELOS DIGITAIS DE REPRESENTAÇÃO DO RELEVO}

A análise morfológica é parte integrante da análise geomorfológica e é comumente exigida nos estudos de VTTs. Esta demanda aparece nos termos de referência como caracterização topográfica ou morfológica e pode ser feita empregando uma abordagem quantitativa e/ou qualitativa.

$$
\text { A avaliação do relevo }
$$

predominantemente quantitativa é denominada de análise morfométrica e demanda o uso de bases altimétricas e/ou modelos digitais de representação do relevo. Em geral, este tipo de mapeamento classifica e combina parâmetros derivados de modelos altimétricos.
Os modelos digitais de representação do
terreno podem receber diferentes
denominações: MDA $\quad$ (Modelo Digital Altimétrico), MDE (Modelo Digital de Elevação), MNT (Modelo Numérico do Terreno), MDT (Modelo Digital do Terreno), MDS (Modelo Digital de Superfície) e outros. É comum o uso do termo MDE, como sendo o modelo que representa o terreno com todos os objetos dispostos sobre ele (inclusive árvores e edificações) e MDT como modelo que representa o terreno propriamente dito, ou seja, o modelo que não leva em consideração os objetos sobre ele dispostos, tais como árvores e edificações (SOPCHAKI, 2016).

O mapeamento morfométrico constitui base importante para a análise geomorfológica e fornece informações relevantes para estudos geotécnicos, geológicos e pedológicos.

A análise qualitativa é denominada de morfológica e busca descrever as formas de relevo a partir da classificação de padrões gerais (recorrentes) das formas observadas no ambiente. As duas abordagens demandam levantamento altimétrico, são complementares e auxiliam o entendimento dos processos que atuam no ambiente. 


\section{ANÁLISE GEOMORFOLÓGICA APLICADA AOS ESTUDOS DE VIAS DE TRANSPORTE TERRESTRE NO \\ BRASIL}

Os modelos digitais de representação do relevo podem ser produzidos especificamente para atender o estudo da VTT ou, obtidos a partir de bases preexistentes, como a exemplo o SRTM (2008), TOPODATA (2008), ASTER (2015), cartas topográficas e outros.

Caso o estudo da via possua levantamento topográfico planialtimétrico em escala adequada às necessidades da via, este poderá ser utilizado para geração do MDE, via uso de ferramentas disponibilizadas pelos SIG's (Sistemas de Informação Geográfica).

Caso a via não possua levantamento altimétrico, a análise morfométrica fica condicionada aos modelos preexistentes ou modelos derivados de cartas topográficas, os quais são inadequados aos estudos de VTTs.

Esta inadequação decorre de diferentes fatores, sendo os principais problemas a baixa acurácia vertical e as alterações decorrentes de processos de filtragem e/ou reamostragem dos dados. Como estes modelos apresentam falhas de preenchimento e baixa resolução espacial, é comum o uso de filtros e interpoladores, os quais modificam os dados originais (MOURA et. al, 2014).

Modelos como SRTM e ASTER, de maior disponibilidade espacial, apresentam resolução espacial de $30 \mathrm{~m}$ e acurácia vertical compatível com escalas menores do que 1:100.000 (GOUVEIA et. al, 2005).

Por sua vez, modelos gerados a partir de cartas topográficas apresentam acurácia altimétrica inferior à escala do próprio mapeamento de origem, em função dos novos erros introduzidos pela captura e tratamento dos dados, bem como pela aplicação dos interpoladores (IBGE, 2005).

Outro problema para a análise morfométrica advém do uso de interpoladores para gerar modelos ou para aumentar a resolução espacial de modelos já existentes. Este procedimento demanda conhecimentos de geoestatística e necessita que seja feita uma análise de seus efeitos sobre os parâmetros morfométricos extraídos.
Os parâmetros morfométricos extraídos dos MDT/MDE são condicionados pela resolução do modelo e pelo processo de obtenção. Assim, diferentes modelos (SRTM, ASTER, etc.) fornecem diferentes parâmetros morfométricos para uma mesma área de análise (altimetria, declividade, curvatura, etc.).

Desta forma, só é possível associar um parâmetro morfométrico obtido em um MDT/MDE a um passivo/processo ambiental, quando se empregam modelos elaborados por procedimentos integralmente idênticos, desde a captura do dado até a etapa de manipulação do MDE em SIG. Ainda assim, esta associação demandaria a análise dos materiais e processos atuantes.

Isto faz com que os valores dos parâmetros morfométricos observados em um dado contexto raramente possam ser empregados como padrão para a realização de outros estudos.

Ravinas, voçorocas e subsidências, que podem resultar em passivos ambientais, apresentam associação com diferentes formas e padrões morfométricos. Isto porque, ainda que a forma seja recorrente, os materiais e processos atuantes são diferenciados entre as diferentes VTT e, por vezes, dentro de uma única VTT.

A diversidade de formas que podem ser associadas a diferentes processos é observada tanto em locais próximos, ao longo de uma única VTT, como em áreas distantes e com distintas características físico-ambientais.

Resumindo, o número de processos e feições geomorfológicas que localmente podem ser relacionadas a determinados parâmetros morfológicos-morfométricos é quase que ilimitado (em função das diferentes formas de obtenção dos dados e escalas e dos diferentes condicionantes ambientais).

Assim sendo, o intervalo de declividade usado para definir áreas preferenciais para ocorrência de processos de subsidência/escorregamento ao longo de um seguimento de determinada rodovia, pode ser completamente inapropriado para definir as mesmas áreas em um trecho de outra rodovia. 


\section{ANÁLISE GEOMORFOLÓGICA APLICADA AOS ESTUDOS DE VIAS DE TRANSPORTE TERRESTRE NO \\ BRASIL}

De forma similar, como exemplo, enquanto as ravinas observadas na borda oeste da Ferrovia Oeste-Leste (FOL EF334) encontramse associadas a vertentes convexas com baixas declividades, na porção centro-leste apresentam maior relação com vertentes planas com declividade moderada e, com vertentes retilíneas de elevada declividade na faixa leste.
Estas variações indicam que os processos em análise encontram-se associados não só a diferentes padrões morfológicosmorfométricos, como também a questões como tipologia e descontinuidades pedológicas e litológicas, regime de precipitação e uso do solo, etc. (Fig. 5).

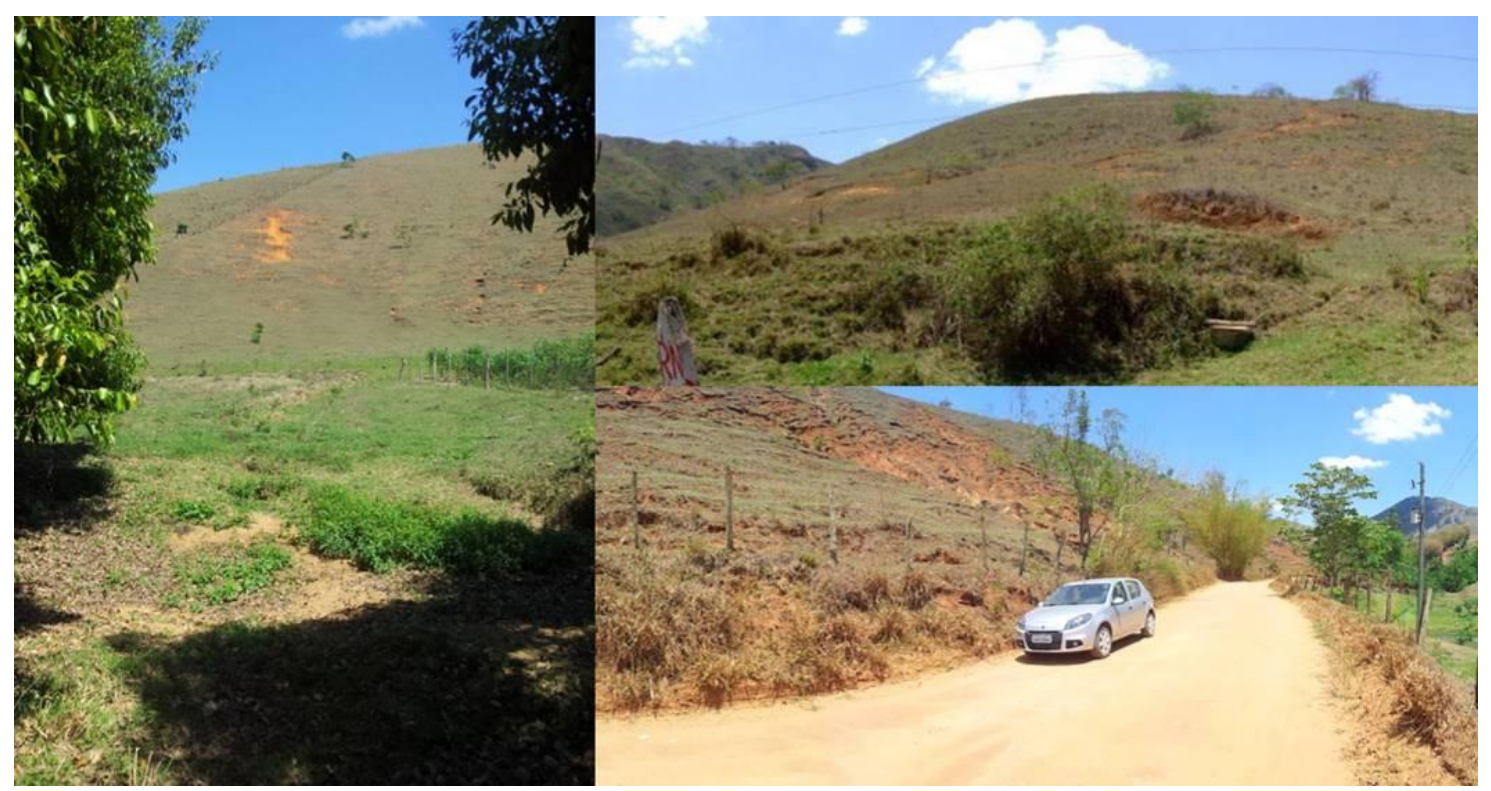

Figura 05 - Ravinas e subsidências em vertentes retilíneas e convexas, na Rodovia RJ-198, embora a literatura associe, normalmente, feições erosivas lineares a formas de vertente côncavas-convergente. Fonte: acervo dos autores (2013).

A constatação de que os parâmetros extraídos de MDT's demandam cuidados para uso em estudos de VTTs não indica que os mesmos não devam ou possam ser utilizados. Estes parâmetros, quando associados às formas e processos atuantes ao longo da via, fornecem subsídios para o planejamento da mesma, especialmente quando associados a dados de clima, solos, geotecnia e geologia.

\subsection{NECESSIDADE DE ADEQUAÇÃO DA ÁREA DE INFLUÊNCIA}

De acordo com os Termos de Referência e Instruções Técnicas, os estudos sobre o meio físico devem ter definidas as áreas de influência direta e indireta dos empreendimentos. Estas áreas deverão ser cobertas pelos estudos que se fizerem necessários, incluindo a análise e mapeamento geomorfológico.

A Área de Influência Direta (AID), em geral, corresponde a Área Diretamente Afetada pelo empreendimento (ADA), enquanto a Área de Influência Indireta (AII) corresponde às áreas "próximas", sendo esta medida variável em função do tipo de empreendimento e, das características do local afetado. Tanto a definição da AID quanto da All, podem variar significativamente de um estudo para outro, em termos de área de abrangência.

Segundo os TR e IT a definição das AID e All deve ser feita pela equipe multidisciplinar responsável pela elaboração do estudo, em etapa de reconhecimento preliminar e, sempre com base na Resolução CONAMA 001/86. 


\section{ANÁLISE GEOMORFOLÓGICA APLICADA AOS ESTUDOS DE VIAS DE TRANSPORTE TERRESTRE NO \\ BRASIL}

Para a definição da AID e All devem ser considerados os tipos de atividades já existentes e a serem desenvolvidas, os ecossistemas, localidades que podem sofrer alterações em decorrência da implantação do empreendimento, fatores ambientais susceptíveis aos efeitos das atividades a serem implementadas e a bacia hidrográfica sob influência da VTT (IBAMA, 2011).

Assim sendo, as áreas de influência devem ser definidas de forma a contemplar as áreas afetadas pelos impactos gerados, desde a etapa de construção até a de operação da via, demarcando assim, os limites da área de estudo a partir de faixas de amortização dos impactos diretos e indiretos.

De acordo com DNIT (2006) a Área de Influência Direta refere-se à:

Área onde atuam diretamente os impactos ambientais originários ou devidos às atividades transformadoras da construção, manutenção, conservação e operação rodoviária, causando danos ou perdas das qualidades existentes no relacionamento dos fatores ambientais que caracterizam esta área, envolvendo no mínimo a faixa de domínio da rodovia e as micro bacias de drenagem, utilizando-se para efeito de avaliação de impacto ambiental, usualmente, de 1,5 a 2,0 km de afastamento do eixo da rodovia. Nesta faixa de território surgem, na maioria das vezes, os danos ambientais diretos, tais como, erosões, assoreamentos, desapropriações, segregações, perdas do patrimônio biótico, supressão da vegetação, etc, ocasionando a redução da qualidade ambiental para os habitantes ou proprietários nesta área.

\section{E, a Área de Influência Indireta refere-se} à:

Área onde atuam indiretamente os impactos ambientais das atividades rodoviárias, devidas às características próprias do meio de transporte rodoviário, retratadas através de ampla distributividade de suas ações, em especial, devido à sua acessibilidade em qualquer região, desde que em seus caminhos se permita a passagem aos seus veículos. Esta grande flexibilidade de deslocamento do meio rodoviário amplia, enormemente, a área de influência dos impactos, englobando toda a rede rodoviária tributária da região em estudo (DNIT, 2006).

O Glossário de termos técnicos ambientais rodoviários (DNIT, 2006) afirma ainda que os limites da All são fixados pela linha de cumeada dos divisores d'água das principais bacias hidrográficas da região, considerando-se também, a influência das principais cidades ou comunidades.

Portanto, no contexto da análise e mapeamento geomorfológico, a definição da AID e All a partir da definição de faixas de amortização fixas e marginais da via ou, buffers como são mais conhecidos, é inadequada por desconsiderar que os processos geomorfológicos possuem diferentes escalas espaciais de ocorrência e interferência, podendo variar desde a escala da vertente até áreas maiores que a própria bacia hidrográfica.

Desta forma, a vertente e a bacia hidrográfica são mais adequadas à análise geomorfológica, apesar de menos usual em estudos aplicados a rodovias e ferrovias. Esta adequação decorre do fato de que permitem a análise dos processos e formas, a partir de diferentes escalas e níveis hierárquicos (terço inferior da vertente, cabeceira de drenagem, bacia de zero ordem, bacia de primeira ordem, segunda ordem, etc).

Caso a definição da AID e All se dê por buffers com valores fixos, caberá à equipe responsável pela análise geomorfológica evidenciar, sempre que necessário, a ampliação destes limites, de modo a permitir a caracterização adequada dos processos que possam exceder aqueles preestabelecidos.

Exemplo de processo que foi desencadeado a mais de $7 \mathrm{~km}$ de distância da rodovia e que gerou estragos em VTTs foi a ocorrência de escorregamentos com corrida de detritos na BR-277 em março de 2011, com a destruição da ponte de uma das vias de rolamento (Figs. 6 e 7). Neste caso, a fonte de materiais que culminou na corrida de detritos e desabamento da ponte estava em locais a mais 
SAMPAIO,T.V.M. e SOPCHAKI, C.H.

\section{ANÁLISE GEOMORFOLÓGICA APLICADA AOS ESTUDOS DE VIAS DE TRANSPORTE TERRESTRE NO}

BRASIL

de $7 \mathrm{~km}$ da rodovia (Fig. 8) e dificilmente estaria

enquadrada como All se fosse aplicado um

buffer.

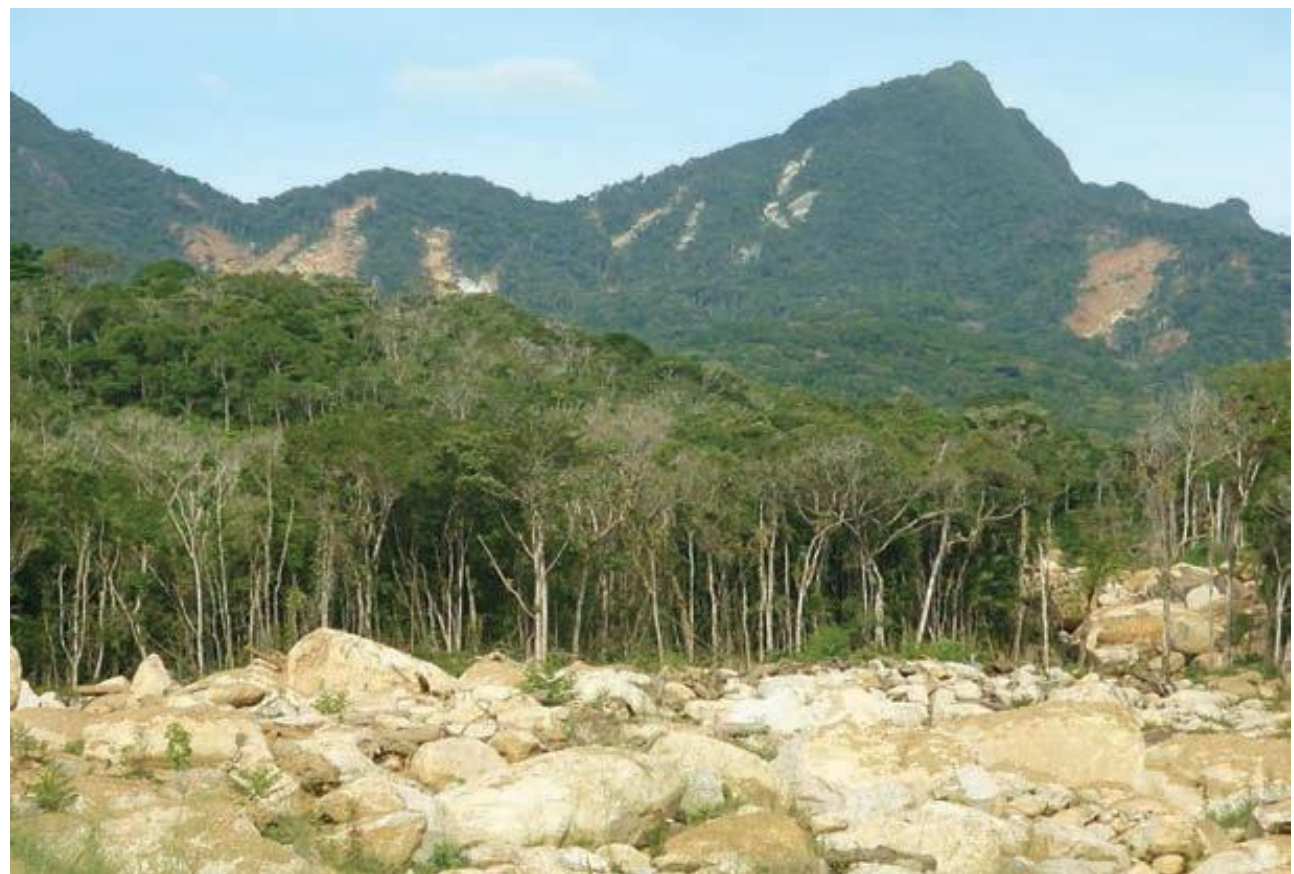

Figura 06 - Cicatrizes dos deslizamentos e matacões que foram transportados até as margens da Rodovia BR-277. Fonte: Pinto et. al (2015).

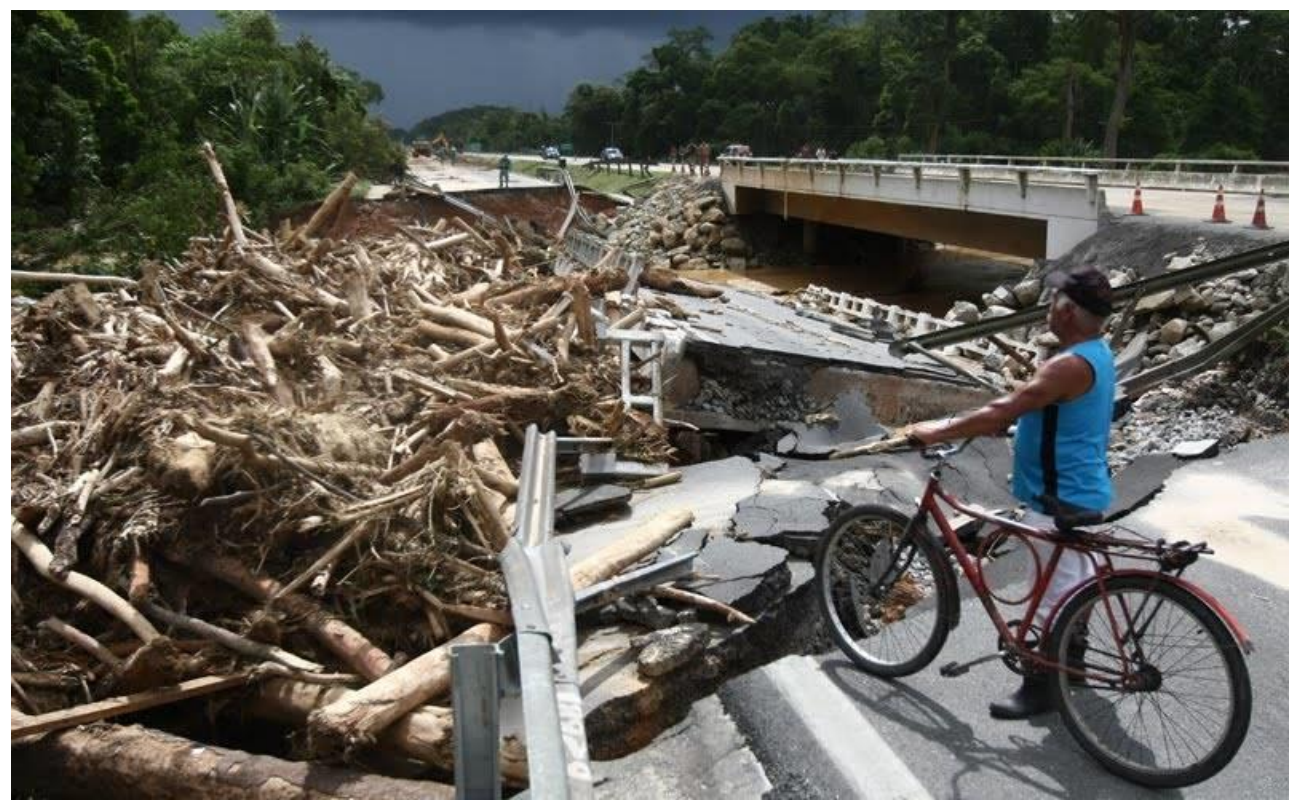

Figura 07 - Ponte sobre o Rio Jacareí - Rodovia BR-277, 11 mar 2011.Fonte: FOTO JORNALISMO CURITIBA (2015). 


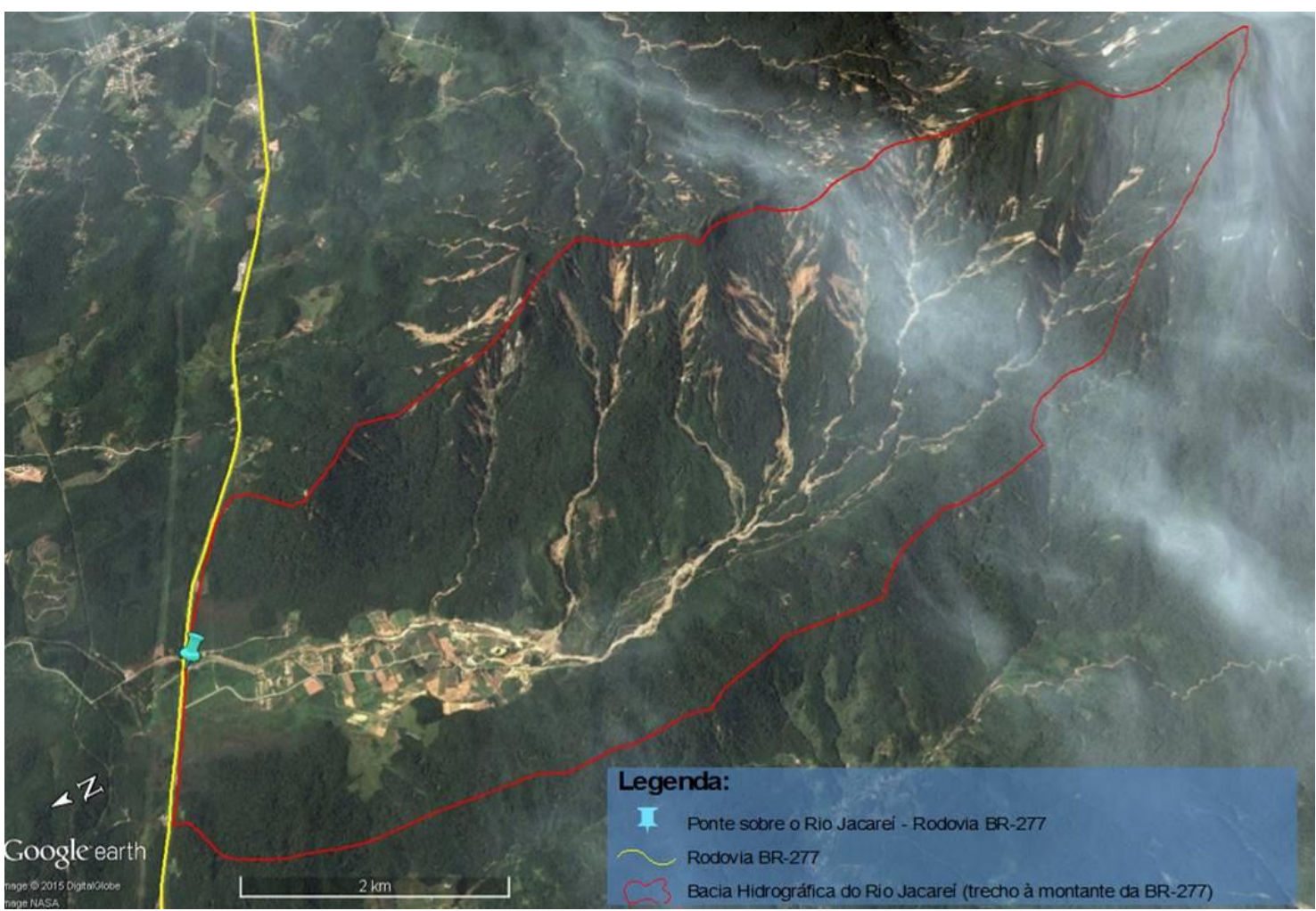

Figura 08 - Imagem de satélite com as cicatrizes dos escorregamentos ocorridos em março de 2011 na Bacia do Rio Jacareí, ao lado da Rodovia BR-277. Neste caso, em algumas áreas a fonte dos materiais transportados até a ponte, os quais culminaram na sua queda, estava a mais de $7 \mathrm{~km}$ da estrada. Fonte: Google Earth (2011), organizado pelos autores (2015).

É importante destacar que boa parte dos TR e IT apresentam maior preocupação com as áreas afetadas pelas vias, portanto acabam tratando as AID e All como sendo somente as áreas que serão impactadas pelas VTT. Contudo, espera-se que a análise geomorfológica extrapole essa visão e delimite as AID e All contemplando as vertentes e/ou bacias hidrográficas que cortam a VTT.

Assim as possíveis áreas de contribuição (áreas de bacias hidrográficas e/ou vertentes que cortam a VTT e que estão à montante desta) que podem transportar material até a VTT, em caso de eventos pluviométricos extremos, podem ser inseridas no mapeamento geomorfológico, ainda que extrapolem as AID e All previamente definidas.

Neste sentido, o mapeamento geomorfológico deve tratar as AID e All como áreas que sofrem influência da VTT e também como áreas que podem influenciar a VTT. Tal cuidado pode diminuir custos na manutenção da VTT, à medida que obras de infraestrutura podem ser feitas a fim de atenuar os riscos com acidentes durante a fase de operação da via.

\section{METODOLOGIAS, TÉCNICAS E FERRAMENTAS PARA O MAPEAMENTO GEOMORFOLÓGICO APLICADO AO ESTUDO DE VIAS DE TRANSPORTE TERRESTRE - VTTS}

\subsection{CONDICIONANTES PARA ESCOLHA DA ABORDAGEM METODOLÓGICA}

Conforme exposto anteriormente, o mapeamento geomorfológico pode ser executado através de diferentes abordagens metodológicas e, por este motivo, os TR e IT não definem uma metodologia a ser empregada. Contudo, cabe destacar que a escolha da 


\section{ANÁLISE GEOMORFOLÓGICA APLICADA AOS ESTUDOS DE VIAS DE TRANSPORTE TERRESTRE NO \\ BRASIL}

metodologia a ser empregada deve levar em conta fatores que interferem diretamente nos estudos e na capacidade de integração dos dados, tais como:

- Necessidade de ênfase na avaliação dos processos e passivos ambientais. 0 mapeamento geomorfológico para o estudo de vias apresenta ênfase na identificação de passivos ambientais e na caracterização da dinâmica ambiental local. Desta forma, a metodologia adotada deve permitir considerar os limites das unidades com diferentes dinâmicas ambientais. Deverá apresentar também os processos geomorfológicos que possam ser gerados/geradores ou modificados/modificadores em função da implantação da via;

- Possibilidade de associação das unidades mapeadas às formas de relevo. De acordo com os TR e IT, a caracterização topográfica (morfologia e/ou morfometria) serve de base para o conjunto de levantamentos que caracterizam o meio físico (em especial geotécnicos e definição de áreas de risco), portanto, a metodologia empregada deve proporcionar a integração das unidades mapeadas com os limites das unidades caracterizadas pelo mapeamento morfológico;

- Necessidade de integração com os demais estudos que compõem o meio físico. A escolha da metodologia deve levar em consideração, sem necessariamente se limitar a estes, as unidades e aspectos relativos à geologia, pedologia, geotecnia, usos do solo, vegetação e clima.

- Disponibilidade de dados auxiliares. A metodologia a ser adotada deve considerar os demais dados disponíveis e observáveis em campo sobre o meio físico. Caso os outros estudos sobre o meio físico ainda não tenham sido realizados, o mapeamento geomorfológico deverá observar, sempre que possível, os limites das unidades geológicas e pedológicas já mapeadas, de forma a garantir a integração dos dados e servir de base para os demais estudos.

- Dimensão da área de estudo. Boa parte dos segmentos estudados são de dimensão reduzida (unidades a dezenas de quilômetros de extensão) e, consideram apenas a faixa de amortização no entorno da via. Portanto o mapeamento deve levar em consideração a reduzida área de mapeamento e, a produção de uma base de dados estreita e longa, sem que haja necessidade de mapear integralmente as unidades territoriais transpostas pela via.

- Independência de mapeamento geomorfológico precedente. Como nem todos estados possuem mapeamento geomorfológico e, os que possuem não necessariamente empregam metodologia similar, o mapeamento com vista a estudo de VTT não pode depender da existência de uma base precedente.

A possibilidade de adoção de diferentes metodologias flexibiliza a realização dos estudos e do mapeamento geomorfológico. Os itens anteriormente relacionados devem nortear a escolha da metodologia, contudo, esta escolha não necessita se restringir a somente os itens aqui relacionados.

Estudos para VTT longas, geralmente com mais de uma centena de quilômetros de comprimento, podem fazer uso das metodologias e levantamentos disponíveis, conforme citado anteriormente. Nestes casos, os estudos adotam como ponto de partida as bases do IBGE e do RADAMBrasil e, de acordo com as referidas metodologias, são definidas as subunidades que se fizerem necessárias.

\subsection{ABORDAGEM METODOLÓGICA PARA ESTUDOS E MAPEAMENTO DE DETALHE}

Outras abordagens metodológicas menos convencionais em território brasileiro merecem destaque para os estudos de vias, por se mostrarem vantajosas em função das características físicas locais, da dimensão da via e da disponibilidade de dados. 


\section{ANÁLISE GEOMORFOLÓGICA APLICADA AOS ESTUDOS DE VIAS DE TRANSPORTE TERRESTRE NO \\ BRASIL}

Em especial, para vias de dimensão reduzida, destacam-se duas metodologias: a baseada na Teoria Geral dos Sistemas, tal qual foi executado o mapeamento geomorfológico do Estado de Goiás (LATRUBESSE et. al, 2005) e a de mapeamento geomorfológico em grande escala, conforme Brunsden et. al (1975), Hearn (2002) e Bell (2013).

A metodologia baseada na Teoria Geral dos Sistemas considera a memória do sistema como base para a identificação das unidades mapeadas, a partir da análise da gênese, evolução e mecanismos internos das unidades mapeadas.

Cada unidade, ou sistema geomorfológico, tem sua estrutura interna definível e caracterizada por variáveis de estado (como: litologia) e de transformação/processos (como: erosão), que se mobilizam por aportes externos de energia e matéria.

As unidades podem ser caracterizadas por seu grau de estabilidade e similaridade interna, aonde unidades estáveis absorvem bem os impactos das perturbações (regulação), enquanto as instáveis reagem rapidamente se modificando em função da nova situação (adaptação).

O critério de classificação das unidades é determinado pela dominância das geoformas, sejam denudacionais (onde ocorre perda de material) ou agradacionais (onde ocorre depósito/ganho de material). A classificação permite a inclusão de diferentes variáveis como por exemplo: processos, solos, condições hidrológicas, vegetação, etc.

As unidades mapeadas podem estar tanto geomorfologicamente ativas, quanto inativas, tais como as ravinas que podem estar estáveis, ou em processo de expansão. Destacase que $o$ fator condicionante para sua delimitação e classificação é a predominância das formas.

A escala é considerada como variável de ajuste, determinada pela interpretação dos distintos elementos geomorfológicos nas diferentes hierarquias, o que torna o sistema classificatório dinâmico.
A segunda metodologia a ser considerada é a proposta por Brunsden et. al (1975), Hearn (2002) e Bell (2013), desenvolvida especificamente para a caracterização de vias de transporte terrestre, e que considera como base de compartimentação a análise de estruturas, processos e feições ambientais.

Em especial, esta metodologia permite ao mapeador considerar elementos hidrológicos que influenciam na estabilidade da via e na definição de feições morfológicas de grandeza reduzida. Apesar de distinta, esta metodologia é muito similar à metodologia baseada na Teoria Geral de Sistemas.

Nesta metodologia, a delimitação das unidades geomorfológicas pode ser feita a partir dos padrões de distribuição espacial: recorrência e predominância das feições, dos processos ambientais e dos materiais envolvidos.

Estas duas metodologias possibilitam o emprego de variáveis diversas, como por exemplo, as formas delimitadas pelo mapeamento morfológico e/ou morfométrico, bases geológicas e pedológicas e, os processos identificados em campo.

Neste sentido, todo padrão morfológico ou morfométrico e toda feição ou padrão de feições observado em campo, pode ser definido como subunidade ou unidade geomorfológica. A depender da escala e da complexidade local, tanto uma planície aluvial como uma sequência de ravinas, podem ser definidas como unidade ou subunidade geomorfológicas.

A possibilidade de incorporação de unidades morfológicas pré-delimitadas, quer sejam observadas em campo ou definidas a partir de produtos do sensoriamento remoto, favorece o trabalho de mapeamento. Isto porque parte dos trabalhos pode ser feita com auxílio dos SIGs, via uso de MDT e imagens orbitais, ampliando a área de visão da equipe de mapeamento para além das áreas visitadas em campo.

Estas metodologias apresentam como vantagens, ainda:

- $\quad$ a facilidade aplicação;

- a possibilidade de ênfase na abordagem da dinâmica ambiental; 


\section{ANÁLISE GEOMORFOLÓGICA APLICADA AOS ESTUDOS DE VIAS DE TRANSPORTE TERRESTRE NO \\ BRASIL}

- a geração de produtos analíticossintéticos;

- $\quad$ a possibilidade de integração com outras bases e estudos do meio físico;

- a aplicação de forma isolada ou complementar aos mapeamentos já existentes;

- a elaboração de mapas em qualquer escala e para qualquer dimensão de via analisada, uma vez que o mapeamento se inicia na identificação e agrupamento de feições menores ou padrões de feições (classificação de baixo para cima ou bottomup);

- a possibilidade de integração com bases geomorfológicas disponíveis em escalas menores (níveis hierárquicos maiores), apesar de não dependerem da existência destes.

Outra característica positiva destas metodologias é a possibilidade de adequação do mapeamento a uma escala preestabelecida e vice-versa, ou seja, de se definir previamente uma escala de trabalho ou, indicá-la a partir das unidades que foram mapeadas.

Isto porque a definição da escala de um mapeamento pode ser definida a partir da análise de três parâmetros: densidade amostral (n amostral), acurácia posicional e dimensão das feições mapeadas (ou nível de generalização). Todos estes parâmetros, que podem atuar de forma isolada ou conjunta na definição da escala, são facilmente identificados quando da aplicação das metodologias anteriormente apresentadas.

O número de pontos amostrados em campo, ou n amostral, é um dos parâmetros que definem o grau de detalhamento de um mapeamento, uma vez que fornece a indicação do grau de completude de feições. O n amostral é uma referência do nível de feições mapeadas em relação àquelas possíveis de serem observadas em campo.

Apesar de não existir uma referência do $\mathrm{n}$ amostral ideal para o mapeamento geomorfológico, como a exemplo do que ocorre nos mapeamentos de solos (EMBRAPA, 2013) e geotécnico (ZUQUETTE e GANDOLFI, 2004), essas metodologias de classificação (bottom-up) pressupõem que todas as unidades mapeadas foram amostradas em campo. Desta forma, o $\mathrm{n}$ amostral deixa de intervir na definição da escala, passando esta a ser função direta da acurácia posicional e do o nível de generalização empregado.

A acurácia posicional é um dos parâmetros mais relevantes a ser observado na definição da escala do mapeamento, uma vez que define o nível de ajustamento dos dados à realidade de campo. No Brasil esta relação é definida pelos Padrões de Exatidão Cartográfica (PEC), constantes no Decreto no 89.817, de 20 de junho de 1984 (BRASIL, 1984) e, para produtos da cartografia digital, pelo PEC-PCD (Padrão de Exatidão Cartográfica para Produtos da Cartografia Digital), estabelecido pela Especificação Técnica para a Aquisição de Dados Geoespaciais Vetoriais - ET-ADGV (DSG, 2011). Deve-se observar também a Especificação Técnica para Controle de Qualidade de Dados Geoespaciais - ET-CQDG (DSG, 2016), cujo objetivo é "fornecer uma forma padronizada para avaliar a qualidade dos produtos de conjuntos de dados geoespaciais integrantes do Sistema Cartográfico Nacional (SCN) do Brasil".

Estas normativas estabelecem a relação entre a acurácia posicional e a escala do mapeamento. Sendo assim, um mapeamento geomorfológico estará na escala $1: 10.000$ se os limites em campo foram definidos com GPS (sigla usada para aparelhos que utilizam o Sistema de Posicionamento Global - GNSS) ou com imagens de satélite com acurácia posicional compatível com esta escala.

A definição da menor unidade mapeada é o terceiro parâmetro a ser considerado para definição da escala final do mapeamento. Esta análise considera o nível de generalização que foi empregado, indicando de forma indireta, a escala do mesmo. Em função da ausência de parâmetros e, considerando as práticas já desenvolvidas e outras referências, sugere-se a adoção de $9 \mathrm{~mm}^{2}$ como dimensão mínima mapeável para estudos de VTTs.

Desta forma, caso se deseje associar o mapeamento à escala 1:10.000, por exemplo, o 


\section{ANÁLISE GEOMORFOLÓGICA APLICADA AOS ESTUDOS DE VIAS DE TRANSPORTE TERRESTRE NO \\ BRASIL}

mesmo deverá apresentar unidades com área igual ou superior a $900 \mathrm{~m} 2$. Neste exemplo, a presença de unidades com dimensões menores que $900 \mathrm{~m}^{2}$ indica, que o mapeamento apresenta grau de detalhamento melhor do que 1:10.000, cabendo nova avaliação de sua escala.

\subsubsection{O INVENTÁRIO DE CAMPO}

O mapeamento geomorfológico pode fazer uso de metodologias, técnicas e ferramentas auxiliares, como a fotointerpretação, o processamento digital de imagens (PDI) e operações de álgebra de mapas, contudo, deve adotar como ferramenta de base o inventário de campo.

O inventário de campo (levantamento de campo) é fundamental para confecção do relatório e do mapa e, tem por finalidade a aquisição dos dados primários. Esta etapa permite o levantamento de informações importantes como: os principais processos atuantes, materiais envolvidos, formas gerais de relevo, feições erosivas e suas dimensões, estruturas e agentes controladores de processos (presença de falhas, solos moles, depósitos), identificação de cursos d'água perenes e intermitentes, etc.

$\mathrm{Na}$ etapa de campo também são coletados e verificados os dados pedológicos, geológicos e hidrográficos disponíveis, possibilitando a validação dos demais dados existentes para área de interesse (fontes primárias e secundárias) e, a realização de possíveis ajustes nas bases cartográficas, e a verificação da adequação do traçado da via.

Neste sentido o estudo e mapeamento geomorfológico pode suceder os demais estudos (geologia, pedologia, geotecnia...) fazendo uso das informações pré-existentes para análise e compartimentação das unidades geomorfológicas ou, preceder os demais estudos, servindo de base para as demais análises.
Partes dos processos geomorfológicos atuantes podem estar relacionados aos passivos da via, que devem ser identificados em campo, como: subsidências, escorregamentos, quedas de blocos, rastejos de solos, erosão em sulco ou lençol, áreas de inundação e outros. Áreas de difícil acesso e mais distantes das VTT podem ser mapeadas após o trabalho do campo (a partir do conhecimento da área adquirido neste), via uso de produtos de sensoriamento remoto, ampliando o conhecimento sobre a recorrência destes na área de estudo.

Recomenda-se o uso de uma ficha para coleta de dados em campo, com a finalidade de organizar os dados coletados e observados no campo, bem como trazer agilidade ao trabalho de campo e maior clareza na etapa de processamento dos dados em gabinete.

É importante que a ficha seja organizada de forma que o profissional despenda menos tempo no trabalho de campo sem, contudo, negligenciar informações importantes, evitandose chegar em gabinete e constatar que faltou alguma informação do campo, como uma coordenada de alguma feição, cor de solo, número de fotografia, ou características gerais do ambiente, por exemplo.

A Figura 9 traz um exemplo de ficha de levantamento de campo, contudo ela é apenas um modelo, pois cada profissional deve adaptar a sua, de acordo com a sua experiência, bem como de acordo com as demandas daquele inventário e das características que puderam ser inferidas sobre a área durante a etapa de preparação para o campo (neste caso, pode-se optar também em colocar campos objetivos para cadastrar feições, como subsidências, ravinas, cursos d'água, entre outras, o que traria um ganho de produtividade em campo). 


\begin{tabular}{|l|l|l|l|}
\hline \multicolumn{5}{|c|}{ Identificação e Localização da VTT } \\
\hline \multicolumn{5}{|c|}{ Coordenadas ponto inicial da via } \\
Código / Nome:
\end{tabular}

Figura 08 - Exemplo de ficha para inventário geomorfológico em VTT.Fonte: elaborado pelos autores (2015).

Com relação às fotografias feitas durante o inventário de campo, cabe destacar que cumprem um importante papel no momento de sistematização dos dados em gabinete e também na etapa de apresentação do relatório, pois a partir delas é possível descrever e sintetizar ambientes e feições. Portanto, recomenda-se o uso de máquinas fotográficas com GPS integrado, o que minimiza o trabalho de tabular as fotografias em campo.

O inventário de campo constitui a condição sine qua non para o mapeamento geomorfológico, sendo o meio pelo qual são identificados os processos e formas associadas aos passivos presentes ao longo da via e, que possam intervir no funcionamento e estabilidade do ambiente e da mesma.

A ausência do inventário de campo limita o estudo geomorfológico à consulta de dados secundários, os quais, conforme exposto anteriormente, apresentam escalas de pouco detalhe e/ou por vezes, remetem o mapeamento à análise somente das formas (morfométrico), a partir da análise de modelos digitais de elevação de baixa resolução espacial. Estes podem não ser adequados aos estudos de vias, uma vez que as formas analisadas são condicionadas pelo MDT utilizado. Além disso, o DNIT recomenda que os levantamentos sejam elaborados preferencialmente a partir de fontes primárias.

Os levantamentos de dados e informações deverão ser realizados tendo como base, preferencialmente, fontes primárias. Estas informações poderão ser complementadas com o uso de fontes secundárias (referências bibliográficas, documentais, cartográficas, estatísticas, imagens de satélite, etc.) obtidas junto a órgão públicos e agências governamentais especializadas, universidades e instituições de pesquisa (DNIT, 2015). 


\section{ANÁLISE GEOMORFOLÓGICA APLICADA AOS ESTUDOS DE VIAS DE TRANSPORTE TERRESTRE NO \\ BRASIL}

Portanto, as informações obtidas durante o inventário de campo podem depois ser complementadas a partir de outras fontes, bem como tais fontes podem servir de subsídio durante a fase de preparação e planejamento para o campo.

Mapeamentos geomorfológicos em geral se apoiam em produtos do sensoriamento remoto (orbital e suborbital), com vista a identificar estruturas, formas e processos presentes e atuantes na área estudo.

Caso a escala das imagens e o nível de experiência do fotointérprete permitam validar os dados inferidos por fotointerpretação, os mesmos podem ser incorporados à análise da etapa posterior. Caso contrário, serão empregados apenas na etapa final do processo de planejamento da via, como auxiliares ao processo de validação dos resultados e identificação/delimitação das unidades geomorfológicas.

Neste sentido, dados referentes à pedologia, à geologia e à cobertura vegetal trazem informações relevantes para o mapeamento geomorfológico da VTT. Tais dados podem ser utilizados tanto na fase pré-campo, quanto na pós-campo.

Se houver disponibilidade de levantamentos pedológicos e geológicos da área em escala compatível com o trabalho a ser executado, os mesmos podem ser transformados e reclassificados, a partir de álgebra de mapas (GOODCHILD, 1987; BURROUGH e MCDONNELL, 1998), em ambiente SIG, na etapa de preparação para o campo. O resultado da álgebra de mapas entre esses dados traz os primeiros indícios de unidades geomorfológicas da área, os quais poderão ser confirmados e/ou refutados em campo, como também ter os seus limites redesenhados.

A cobertura vegetal é também um outro indicador de possível mudança de unidade geomorfológica, portanto deve-se ter atenção especial com relação a esse dado, tanto na etapa de pré-campo, a partir de imagens de satélite, bem como durante a realização do inventário de campo, onde pode-se perceber as diversas transições de vegetação com maior clareza.

Outro dado que pode trazer indicativos de unidades geomorfológicas para mapeamentos em escalas de detalhe refere-se aos pontos de ruptura da declividade (knickpoints). Mudanças de declividade expressas através das linhas de ruptura do relevo em geral coincidem com limites de unidades geomorfológicas (AUGUSTIN, 1995). A aplicação deste elemento deve levar em consideração o grau de detalhamento do MDT, ou seja, sua compatibilidade com o trabalho em execução.

A partir do mapa geomorfológico gerado, caso seja necessário, é possível desmembrá-lo em mapa geológico e mapa pedológico, pois em mapeamentos geomorfológicos em escala de detalhe, os limites e unidades dos três mapeamentos (geomorfologia, geologia e pedologia) serão muito similares. Contudo para que isso seja possível é necessário que os dados de pedologia e litologia sejam devidamente amostrados e tabulados durante o trabalho de campo.

Com relação à elaboração do mapa geomorfológico final, ressalta-se que esta etapa deverá ser precedida do cuidado em relação à adequação das terminologias, toponímias e níveis hierárquicos desejados. Finalmente, deve-se ainda ter atenção para elaborar o mapa na projeção cartográfica solicitada no TR ou IT e também não negligenciar nenhum elemento obrigatório do mapa (título, legenda, escala, orientação e projeção cartográfica, fonte). Conforme exposto anteriormente, em alguns casos é necessário ainda a adequação da escala do mapa, a partir de operações de generalização cartográfica.

\section{CONSIDERAÇÕES FINAIS}

A análise geomorfológica é parte obrigatória dos estudos sobre vias de transporte terrestre (DNIT, 2006), sendo a responsável pela caracterização dos processos, materiais e formas que afetam a segurança destas.

A escolha da metodologia e da escala é de fundamental importância para os estudos 


\section{ANÁLISE GEOMORFOLÓGICA APLICADA AOS ESTUDOS DE VIAS DE TRANSPORTE TERRESTRE NO \\ BRASIL}

geomorfológicos, pois define o grau de detalhamento, a forma de abordagem e de integração dos dados. O $\mathrm{n}$ amostral empregado nos estudos geomorfológicos e a acurácia posicional dos dados de entrada são os principais elementos definidores do seu grau de detalhamento e escala.

Das metodologias existentes, destacamse a baseada na Teoria Geral dos Sistemas (aplicada por LATRUBSSE et. al, 2005) e a proposta por Brunsden et. al (1975), Hearn (2002) e Bell (2013), desenvolvida especificamente para a caracterização de vias de transporte terrestre, uma vez que permitem considerar os elementos hidrológicos, processos identificados em campo e as formas delimitadas pelo mapeamento morfométrico.

Dentre as técnicas e ferramentas auxiliares aos estudos de VTTs, destacam-se o inventário de campo e as operações de álgebra de mapas em ambiente SIG. O trabalho e o inventário de campo são a base para validação dos dados e proposição de ajustes nas bases cartográficas e no traçado da via.

A definição das áreas de influência direta e indireta deve ser feita de forma cuidadosa pela equipe responsável pelos estudos do meio físico, uma vez que pode variar significativamente de acordo com as características locais.

Faixas de amortização fixas e marginais à via (buffers) podem ser inadequadas aos estudos geomorfológicos, cabendo a equipe responsável pelo estudo evidenciar, sempre que necessário, a ampliação destes limites, incluindo possíveis áreas que possam afetar ou ser afetadas pela VTT.

Nos estudos geomorfológicos todos os passivos ambientais devem ser identificados e relacionados aos demais dados do meio físico, indicando-se as soluções possíveis para preservação do ambiente e das VTTs.

As unidades mapeadas nestes estudos devem apresentar relação direta com os demais elementos do meio físico: geologia, pedologia, vegetação e clima, servindo como fonte de dados e síntese do ambiente.
Neste sentido, a análise geomorfológica aplicada ao estudo de VTTs evita, mitiga e ajuda a compensar os impactos mais significativos desde as fases de planejamento, à de execução e operação das vias, uma vez que integram as informações necessárias ao entendimento e planejamento das mesmas.

\section{REFERENCIAS}

AUGUSTIN, C. H. R. R. Geoökologische Studien im Südlichen Espinhaço Gebirge bei Gouveia, Minas Gerais, Brasilien unter Besonderer Beucksichtigung der Landschaftsentwicklung. [s.I.] Universidade de Frankfurt - Alemanha, 1995.

ASTER - Advanced Spaceborne Thermal Emission and Reflection Radiometer. Disponível em: <http://asterweb.jpl.nasa.gov/>. Acesso em: 05 nov 2015.

BELL, F. G. Fundamentals of engineering geology. Elsevier, 2013.

BRASIL. Decreto no 89.817, de 20 de junho de 1984. Estabelece as instruções reguladoras das normas técnicas da cartografia nacional. Diário Oficial da União, Brasília, DF, 22 jun 1984.

BRUNSDEN, D.; DOORNKAMP, J. C.; FOOKES, P. G.; JONES, D. K. C.; KELLY, J. M. H. Large scale geomorphological mapping and highway engineering design. Quarterly Journal of Engineering Geology, v. 8, n. 3, 1975.

BURROUGH, P. A.; MCDONNELL, R. A. Principles of geographical information Systems. Oxford University Press, 1998.

COELHO NETTO, A. L. Análise e Qualificação Sócio-Ambiental do Estado do Rio de Zoneamento Ecológico Econômico: Relatório da etapa $\mathrm{V}$ regiões hidrográficas de Macaé e Rio das Ostras (RH-VII), Baixo Paraíba do Sul (RH-IX) e Itapoana (RH-X). Rio de Janeiro: [s.n.], 2008.

CPRM - SERVIÇO GEOLÓGICO DO BRASIL. Dignóstico Geoambiental do Estado do Rio de Janeiro. Rio de Janeiro: [s.n.], 2000.

DNIT. Glossário de termos técnicos ambientais rodoviários. Rio de Janeiro, 2006.

DNIT. Diretrizes Básicas para Elaboração de Estudos e Projetos Rodoviários - escopos básicos / instruções de serviço. Rio de Janeiro: [s.n.]. Disponível em: <http://www1.dnit.gov.br/anexo/outros/outros_ 


\section{ANÁLISE GEOMORFOLÓGICA APLICADA AOS ESTUDOS DE VIAS DE TRANSPORTE TERRESTRE NO \\ BRASIL}

edital0457_10-06_1.pdf>. Acesso em 09 jun 2015.

DNIT. Anexo I - Termos de Referência. Disponível em:

<www1.dnit.gov.br/anexo/outros/outros_edital0 493_09-11_1.pdf>. Acesso em 05 nov 2015.

DSG - DIRETORIA DO SERVIÇO GEOGRÁFICO. Especificação técnica para a aquisição de dados geoespaciais vetoriais (ET-ADGV). Versão 2.1.3, 2011.

DSG - DIRETORIA DO SERVIÇO GEOGRÁFICO. Especificação técnica para controle de qualidade de dados geoespaciais (ET-CQDG). 1ae ed., 2016.

EMBRAPA. Sistema brasileiro de classificação de solos. Centro Nacional de Pesquisa de Solos: Rio de Janeiro, 2013.

FOTO JORNALISMO CURITIBA. A BR-277 como você nunca viu. Disponível em: <http://fotojornalismocuritiba.blogspot.com.br/2 011/03/br-277-como-voce-nunca-viu.html>.

Acesso em 05 nov 2015.

GOODCHILD, M. F. A spatial analytical perspective on geographical information systems. International journal of geographical information system, v. 1, n. 4, p. 327-334, 1987.

HEARN, G. J. Engineering geomorphology for road design in unstable mountainous areas: lessons learnt after 25 years in Nepal. Quarterly journal of engineering geology and hydrogeology, v. 35, n. 2, p. 143-154, 2002.

IBAMA. Portaria no 420, de 26 de outubro de 2011. Dispõe sobre procedimentos a serem aplicados pelo IBAMA na regularização e no licenciamento ambiental das rodovias federais. Brasília, DF, 26 out 2011.

IBGE. Manual técnico de geomorfologia. Rio de Janeiro : IBGE, 2005.

INEA - INSTITUTO ESTADUAL DO AMBIENTE. INSTRUÇÃO TÉCNICA CEAM/DILAM № 03/2015. Disponível em:

<http://www.inea.rj.gov.br/cs/groups/public/doc uments/document/zwew/mdc5/ edisp/inea0079 400.pdf>. Acesso em 08 jun 2015.

LATRUBESSE, E. M.; CARVALHO, T. M.; STEVAUX, J. C. Mapa Geomorfológico do Estado de Goiás. Série Geologia e Mineração. Secretaria de Indústria e Comércio, Superintendência de Geologia e Mineração-Goiás. Goiânia, 2005.
MEDEIROS, J. S. de; CÂMARA, G. Geoprocessamento para projetos ambientais. INPE, São José dos Campos - SP, 2001.

OIKOS. Estudo de Impacto Ambiental (EIA) das Obras de Implantação da Ferrovia Oeste-Leste (EF 334), entre Figueirópolis (TO) e Ilhéus (BA). Rio de Janeiro: [s.n.], 2010.

PINTO, R. C.; CANEPARO, S. C.; PASSOS, E. Avaliação Multicritério integrada aos Sistemas de Informações Geográficas para geração de cenário de suscetibilidade a deslizamentos rápidos em vertentes. Atas das I Jornadas Lusófonas de Ciências e Tecnologias de Informação Geográfica. Universidade de Coimbra, 2015.

RADAMBRASIL. Projeto RadamBrasil 1973-1983. Levantamento de Recursos Naturais. Ministério das Minas e Energia.

ROSS, J. L. S. O registro cartográfico dos fatos geomorfológicos e a questão da taxonomia do relevo. Revista do Departamento de GeografiaUSP, n. 6, p. 17-29, 1992.

ROSS, J. L. S. Análises e sínteses na abordagem geográfica da pesquisa para o planejamento ambiental. Revista do Departamento de Geografia (USP), v. 9, p. 65-75, 1995.

SAMPAIO, T. V. M.; AUGUSTIN, C. H. R. R. Análise das incongruências dos índices de dissecação e rugosidade. Anais do VII Encontro Nacional de Geomorfologia. Anais...Belo Horizonte: 2008.

SAMPAIO, T. V. M.; AUGUSTIN, C. H. R. R. Índice de concentração da rugosidade: uma nova proposta metodológica para o mapeamento e quantificação da dissecação do relevo como subsídio a cartografia geomorfológica. Revista Brasileira de Geomorfologia, v. 15, p. 47-60, 2014.

SILVA, L. A.; NAZARENO, N. R. X. de. Análise do padrão de exatidão cartográfica da imagem do Google Earth tendo como área de estudo a imagem da cidade de Goiânia. Simpósio Brasileiro de Sensoriamento Remoto (SBSR), v. 14, p. 17231730, 2009.

SOPCHAKI, C. H. Influência do $\mathrm{N}$ amostral e das características do relevo na qualidade de modelos digitais do terreno. Tese (doutorado) Universidade Federal do Paraná, Setor de Ciências da Terra, Programa de Pós-Graduação em Geografia. 161 f. Curitiba, 2016. 
SRTM - Shuttle Radar Topography Mission, 2008. Disponível em: <http://srtm.usgs.gov/data/obtainingdata.html>. Acesso em 05 nov 2015.

TOPODATA. Banco de Dados Geomorfométricos do Brasil. INPE, 2008. Disponível em: <http://www.dsr.inpe.br/topodata/>. Acesso em 05 nov 2015.

ZUQUETTE, L. V.; GANDOLFI, N. Cartografia geotécnica. São Paulo: Oficina de Textos, 2004. 